\title{
Gênese dos arenitos de praia no litoral de Pernambuco interpretada através de estudos isotópicos
}

\author{
Genesis of beachrock in coast of Pernambuco interpreted by isotopic \\ studies
}

\author{
Antônio Vicente Ferreira $\mathbf{J r}^{\text {ac }}$, Tereza Cristina Medeiros de Araújo ${ }^{\text {ad }}$, Alcides Nóbrega Sial ${ }^{\text {be }}$ \\ ${ }^{a}$ Laboratório de Oceanografia Geológica (LABOGEO), Departamento de Oceanografia, UFPE. \\ bNEG-LABISE, Departamento de Geologia, UFPE. \\ cantonio.vicente@ufpe.br, ${ }^{\mathrm{d}} \mathrm{tcma} @$ ufpe.br, ${ }^{\mathrm{e}}$ sial@ufpe.br
}

\begin{abstract}
RESUMO
Este estudo fez uma análise paleoambiental e paleoclimática por meio de isótopos de oxigênio e carbono do cimento dos arenitos de praia no litoral de Pernambuco. O arenito de praia apresenta valores de $60 \%$ a $85 \%$ do arcabouço composto por grãos detríticos de quartzo. O cimento carbonático é constituído de calcita rica em $\mathrm{Mg}$. Foram obtidos valores de $-1,1 \%$ a $3,5 \%$ para $\delta^{13} \mathrm{C}$ e de $-0,9 \%$ a $0,5 \%$ para $\delta^{18} \mathrm{O}_{\mathrm{VPDB}}$. Estes valores isotópicos são típicos de cimento carbonático marinho, depositados em ambiente marinho raso, sob influência de água doce (ambiente meteórico vadoso) implicando em cimentação na zona de estirâncio. Paleotemperaturas dos cimentos de arenitos de praia variaram de $22,8^{\circ} \mathrm{C}$ a $28,2^{\circ} \mathrm{C}$. Essa variação está relacionada ao aumento da profundidade de precipitação do cimento e indica que a temperatura da água se manteve relativamente constante durante o processo de deposição do cimento carbonático.
\end{abstract}

Palavras-chave: Arenitos de praia; cimentação; composição isotópica.

\begin{abstract}
This study is a paleoenvironmental and paleoclimatic analysis of beachrocks through oxygen and carbon isotopes on its cement. The beachrocks have from $60 \%$ to $85 \%$ of its basis formed by detrital grains of quartz and its carbonate cement is composed by Magnesium-rich calcite. Isotopic values from $-1.1 \%$ to $3.5 \%$ were obtained for $\delta^{13} \mathrm{C}$ and from $-0.9 \%$ to $0.5 \%$ for $\delta^{18} \mathrm{O}_{\mathrm{VPDB}}$. Those values are typical of those from sea carbonate cement deposited on shallow marine environment and under the influence of fresh water (meteoric vadose environment), which causes cementation on the foreshore zone. Paleotemperature of the beachrock cement ranged from $22.9^{\circ} \mathrm{C}$ to $28.2^{\circ} \mathrm{C}$. This variation is due to the rise of the precipitation depth of the cement and indicates that the water temperature was fairly constant during the process of deposition of the carbonate cement.
\end{abstract}

Keywords: Beachrocks; cementation; isotopic composition.

\section{Introdução}

Arenitos de praia ou beachrocks são sedimentos litificados na zona intermaré e formados mediante a precipitação de carbonato de cálcio. Em geral, estão dispostos paralelamente à linha de costa e apresentam forma alongada e estreita. De acordo com Russel (1962), a ocorrência desses corpos rochosos é restrita a regiões tropicais e subtropicais ou ao cinturão quente, entre as latitudes de $35^{\circ} \mathrm{N}$ e $35^{\circ} \mathrm{S}$. Entretanto, alguns autores (Rey et al. 2004, Kneale \& Viles 2000, Omoto 2001, Vousdoukas et al. 2007) apontam a presença de arenitos de praia em zonas temperadas e frias, mesmo que sejam corpos com formação incipiente, como ocorre na Espanha, Portugal, Itália, Grécia, Escócia e Japão, entre outros.
Diversos autores, a exemplo de Ginsburg \& James (1953), Mabesoone (1964), Alexandersson (1972), Beier (1985), Jones et al. (1997), postulam que os arenitos de praia são formados a partir de precipitação carbonática, incluindo vários tipos de cimentação de calcita e aragonita, sendo litificados na zona litorânea com um a dois metros de profundidade. Encontram-se dispostos paralelamente à linha de costa na forma de faixas longas e estreitas, separadas umas das outras por depressões onde são depositadas areias ou lama.

Arenitos de praia no nordeste do Brasil foram descritos pela primeira vez por Darwin (1841), que se referiu a arenitos calcíferos com fragmentos de conchas e raros seixos, alinhados paralelamente à linha de costa. Foi Branner (1904), entretanto, quem propôs que os arenitos de praia representariam antigas linhas de praia, consolidadas por carbonato de cálcio. 
O trabalho teve por objetivo apresentar as condições sob as quais ocorreu a litificação que originou os arenitos de praia, localizados na zona costeira e plataforma continental dos municípios de Paulista, Olinda, Recife e Jaboatão dos Guararapes, no estado de Pernambuco (figura 1). O método utilizado foi a análise da razão isotópica de carbono e oxigênio, comumente utilizado em estudos paleoambientais e paleoclimáticos; na determinação de mudanças de temperatura dos oceanos, ao longo da história da Terra; e na identificação de variações químicas e físicas, nos diferentes ambientes deposicionais.

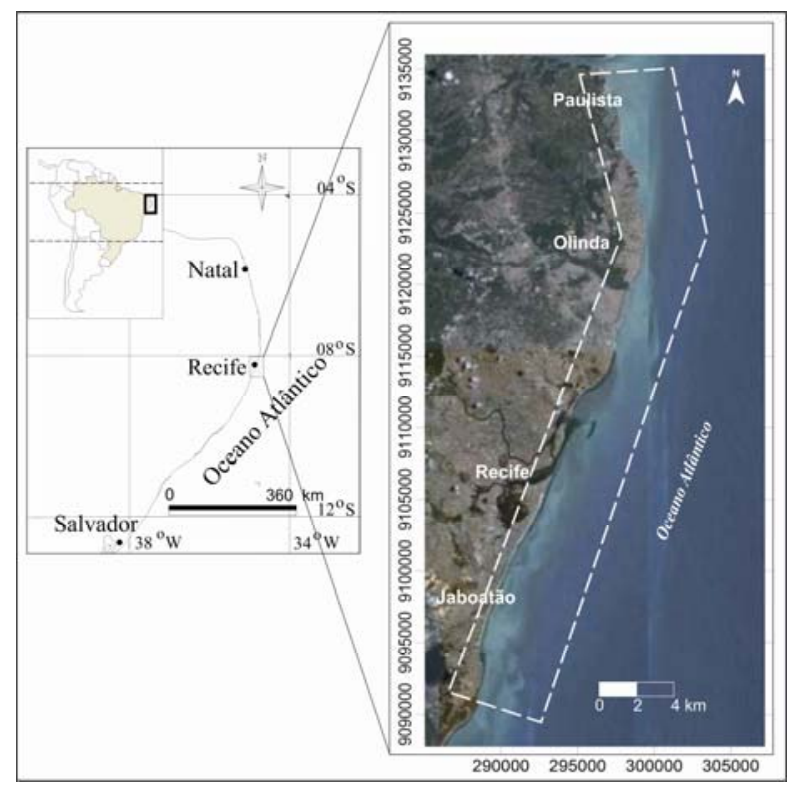

Figura 1: Localização da área de estudo Fonte: Google Earth ${ }^{\mathrm{TM}}$

Os arenitos de praia estudados dispõem-se paralelamente à linha de costa atual e se apresentam predominantemente sob forma linear, com largura de até dezenas de metros em faixas descontínuas e com extensão máxima em torno de $1 \mathrm{~km}$ (figura 2). $\mathrm{O}$ acamamento sedimentar apresenta mergulhos de $10^{\circ}$, em média, no sentido do mar. Em geral, estas rochas ficam submersas durante o período de maré alta. As estruturas sedimentares não se apresentam claramente identificáveis, mas podem ser comparadas com as de praias modernas, com ocorrência de estratificações cruzadas de baixo ângulo e cruzadas acanaladas.

\section{Materiais e Métodos}

Para este trabalho foram coletadas amostras em trechos considerados mais expressivos dos arenitos de praia, com melhor representação das estruturas e perfis de cotas mais altas. Assim, foram coletadas 32 amostras, das quais 27 seções delgadas foram preparadas no Laboratório de Laminação da UFRN, com posterior observação por microscópio petrográfico, no Laboratório de Microscopia do Departamento de Geologia da UFPE.

Utilizaram-se, também, neste estudo, as análises por microscopia eletrônica de varredura (MEV) com o objetivo de observar detalhadamente as características texturais do cimento carbonático, além de análises de raio $\mathrm{X}(\mathrm{EDX})$, que permitiram a identificação de espectros característicos do material analisado, indicando as concentrações relativas dos elementos químicos presentes. As análises foram realizadas no Laboratório de Microscopia Eletrônica de Varredura do Instituto de Geociências da Universidade de Kiel, Alemanha, utilizando-se o modelo CanScan CS-44.

As análises de isótopos estáveis de oxigênio e carbono foram realizadas no Laboratório de Isótopos Estáveis (LABISE) da UFPE. Analisaram-se 32 amostras, sendo retirados, primeiramente, os bioclastos da rocha total, com auxílio de microscópio, e sem separação dos diferentes cimentos. Na primeira etapa, o pó das amostras reagiu com ácido ortofosfórico a $100 \%$, a $25^{\circ} \mathrm{C}$, durante 12 horas. $\mathrm{O} \mathrm{CO}_{2}$ liberado durante a reação foi extraído em uma linha de alto vácuo, empregando purificação criogênica, segundo o método de Craig (1957). Os resultados obtidos são reportados em partes por mil (\%o), relativamente ao padrão internacional VPDB (Vienna PeeDee Belemnite).

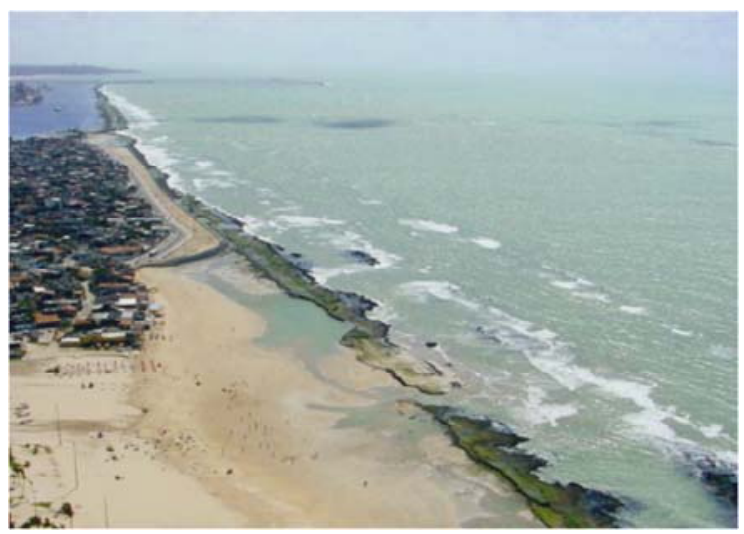

Figura 2: Fotografia aérea oblíqua, em baixa-mar, com destaque para o arenito de praia nas praias do Pina e Brasília Teimosa, em Recife Fonte: Agência Estadual de Meio Ambiente de Pernambuco

\section{Resultados e Discussão}

\subsection{Petrografia}

As análises petrográficas das diferentes seções delgadas auxiliaram na determinação da textura, composição do arcabouço, porosidade, eventos diagenéticos e classificação da rocha.

Os arenitos de praia estudados possuem granulação dominante da fração areia média a grossa, com algumas intercalações de grânulos e seixos, segundo a classificação de Wentworth (1922). Os grãos são pobremente selecionados, variando a forma de subangulosos a subarredondados. O empacotamento é do tipo frouxo, segundo a classificação de Kahn (1956), reflexo da predominância de grãos flutuantes imersos na matriz e/ou cimento (figura $3 \mathrm{~A}$ ).

A composição mineralógica dos grãos é principalmente quartzo (variação modal de 58\% a $85 \%$ ), com predominância do tipo monocristalino (30\% a $77 \%)$ e, em menor número, do policristalino 
( $1 \%$ a $50 \%$ ). Os grãos de feldspato estão presentes em quase todas as seções delgadas examinadas, com concentração em torno de $5 \%$, sendo representados, principalmente, por plagioclásio (figura 3B). Os minerais pesados apresentam-se em pequena porcentagem e são constituídos principalmente por opacos, turmalina, granada, epidoto e zircão (figura 3C), ocupando no máximo $4,5 \%$ do volume. Os bioclastos são constituídos por briozoários, gastrópodes, bivalves, foraminíferos (figura 3D), algas vermelhas e equinoides ocupando em média de $-0,5 \%$ a $9,5 \%$ do arcabouço, sendo os organismos fósseis do tipo bentônicos e planctônicos associados ao ambiente de plataforma rasa.
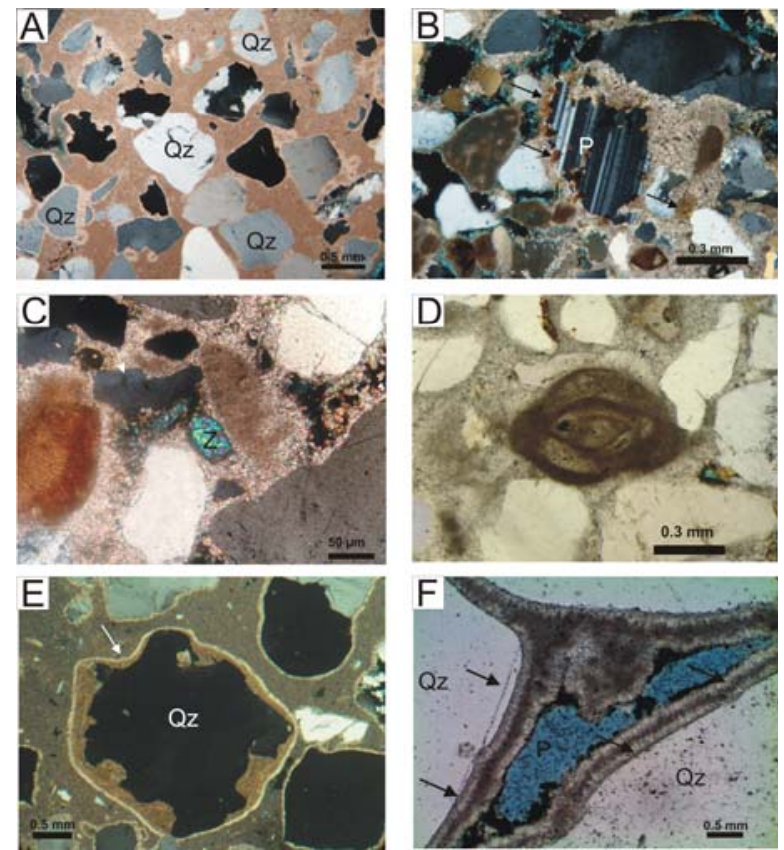

Figura 3: (A) Aspecto geral da rocha com presença abundante de grãos de quartzo $(\mathrm{Qz})$, imersos na matriz. Polarizadores cruzados (PX). (B) Detalhe de grão de plagioclásio (P) parcialmente substituído por cimento carbonático. Presença de hidróxido de ferro (setas), provável contribuição dos sedimentos terciários da Formação Barreiras. PX. (C) Detalhe de grão de zircão (z). PX. (D) Em destaque, no centro da imagem, foraminífero do tipo quinqueloculina. Polarizadores paralelos $(\mathrm{P} / /)$. (E) Grão de quartzo monocristalino $(\mathrm{Qz})$ incrustado por alga vermelha envolvida por franja de cristais prismáticos (seta). PX. (F) Duas gerações de franja de cristais prismáticos separadas por cutícula micrítica (setas). $\mathrm{P} / /$.

\subsection{Composição do Cimento Carbonático}

O cimento carbonático encontrado nas amostras é constituído, exclusivamente, de cristais de calcita altamente magnesiana, como confirmado por espectroscopia de energia dispersada, preenchendo parcial ou completamente os espaços inter e intragranulares. A forma dos cristais é em sua maioria rômbica, com diâmetro entre 4 e $30 \mu \mathrm{m}$. Verificam-se, também, grãos de quartzo monocristalino incrustados por alga vermelha envolvida por franja de cristais prismáticos (figura $3 \mathrm{E}$ ).

Nas amostras selecionadas, os cimentos apresentamse com hábitos e formas variadas (figuras $3 \mathrm{~F}$ e 4 ). As principais formas encontradas foram:
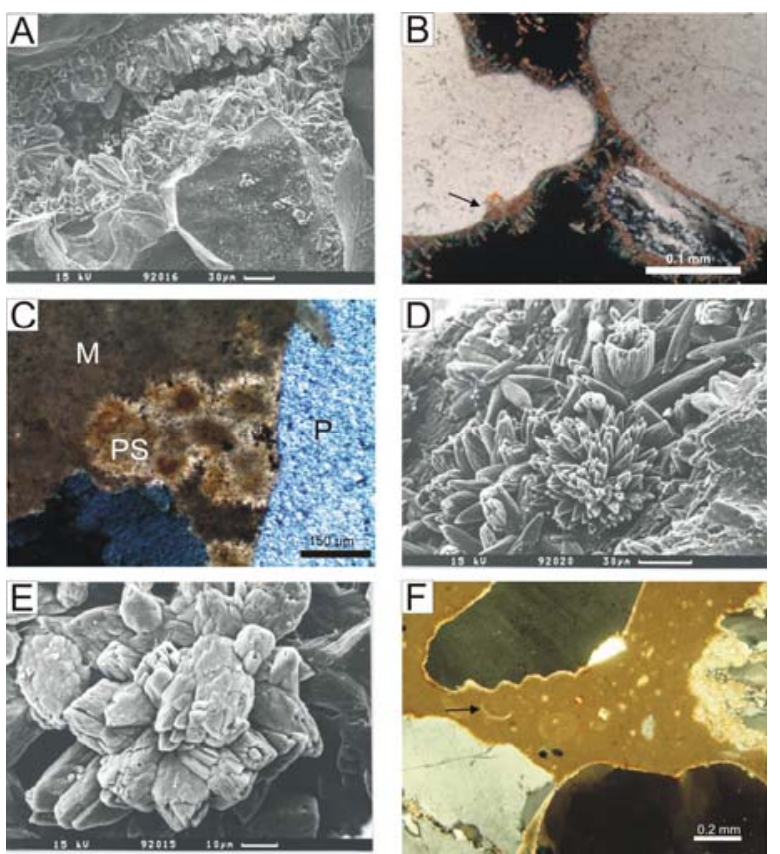

Figura 4: (A) Franja de cristais prismáticos, regular e isópaca, com dimensão entre 5 e $50 \mu \mathrm{m}$, ao redor dos grãos de quartzo. Observar a orientação subperpendicular dos cristais em relação ao grão de quartzo. Imagem obtida ao microscópio eletrônico de varredura (MEV). (B) Franja de cristais prismáticos subperpendiculares a caóticos ao redor dos grãos e película de hidróxido de ferro envolvendo os grãos de quartzo (seta). PX. (C) Espaço poroso (P) ocupado por agregado pseudopeloidal (PS) e cimento micrítico (M). PX. (D) Agregados fibro-radiais, dispostos ao redor dos grãos, com dimensão, em média, de $60 \mu \mathrm{m}$. MEV. (E) Detalhe dos cristais equigranulares, ocupando o espaço poroso. MEV. (F) Marga infiltrada ocupando espaço poroso com presença de fragmento de concha (seta). PX

1. Cutícula criptocristalina: este cimento envolve, em maior número, os grãos siliciclásticos e, em menor número, os bioclásticos, possuindo espessura heterogênea (mínimo de 10 e máximo de $120 \mu \mathrm{m})$ e predominantemente descontínua. Em geral, este cimento é coberto por franja isópaca, sendo uma textura comum em arenitos de praia recentemente cimentados, podendo separar duas gerações da mesma (figura 3F). Esse tipo de textura representa, em média, 2,5\% da frequência total das amostras analisadas, sendo o volume máximo de $6,3 \%$. Sua presença indica que foi desenvolvido sob condições freáticas marinhas. A cutícula criptocristalina apresenta-se como o estágio inicial de cimentação dos arenitos de praia, enquanto a infiltração de marga com bioclastos indica um estágio final de diagênese.

2. Franja prismática isópaca: representa 3,6\%, em média, da frequência total das seções delgadas analisadas, sendo o valor máximo de 7,5\%. Em geral, a franja apresenta forma isópaca muito regular, mas os cristais prismáticos podem se apresentar subperpendiculares ao redor dos siliciclastos (figuras 4A e 4B), enquanto nos grãos de bioclastos, em sua maioria, são perpendiculares à sua superfície. Observou-se, 
também, em algumas seções delgadas, a presença da franja isópaca apenas ao redor de bioclastos. A ausência ou truncamento dos cristais prismáticos é decorrente tanto da dissolução por água doce ou da interrupção do seu crescimento na interface água-ar, na zona vadosa (Neumeier, 1999).

3. Agregados pseudopeloidais: possuem forma esférica a subesférica, com 40 a $100 \mu \mathrm{m}$ de diâmetro. Seu arranjo é bastante espaçado e variado, podendo preencher totalmente os espaços intergranulares das seções delgadas. Estão presentes em praticamente metade das amostras analisadas, representando em média $4,5 \%$ do volume total delas, sendo o valor máximo de 14,5\%. Estão associados, sobretudo, ao cimento micrítico e à franja isópaca.

4. Agregados fibroradiais: foram identificados em poucas amostras, dispostos radialmente a partir do núcleo, em geral isolados ou associados aos cimentos pseudopeloidais ou cristais equigranulares (figuras 4C e 4D). Constituem, em média $2 \%$ do volume total encontrado nas amostras analisadas, com volume máximo de $5 \%$.

5. Cimento micrítico: foi encontrado em mais de $60 \%$ das amostras analisadas. Sua textura apresenta-se como uma massa escura homogênea, preenchendo completamente os espaços intra e intergranulares. É composto por cristais microcristalinos com tamanho máximo de $4 \mu \mathrm{m}$, sendo encontradas, em algumas seções delgadas, pequenas impurezas formadas principalmente de pequenos grãos detríticos. Este cimento representa, em média, 9\% do volume total das amostras analisadas, sendo o valor máximo de $22 \%$ (figura $4 \mathrm{C}$ ).

6. Cimento equigranular: este cimento é formado por agregados de cristais anédricos e subédricos de calcita que preenchem completamente os poros, sob a forma de meniscos ou cimentos pendulares (figura 4E). Com granulometria fina, predomina o tamanho de microcristalino. Constitui em média $6 \%$ do volume total encontrado nas amostras analisadas, com volume máximo de 14\%. Além dessas fases cimentantes, identificou-se marga infiltrada, composta por bioclastos (incluindo planctônicos), seguidos por grãos detríticos (sobretudo quartzo), flutuando em uma mistura de micrita e argila. Possui estrutura maciça, preenchendo a porosidade interpartícula e, em alguns casos, os poros intrapartículas de bioclastos (figura 4F). Constitui, em média, 14\% de material constituinte, nas amostras analisadas, com valor máximo de $25 \%$. Sua eventual ocorrência sob a forma de meniscos ou cimentos pendulares é um indicativo de deposição em ambiente vadoso marinho, conforme apontado por Longman (1980).

\subsection{Isótopos de Oxigênio e Carbono}

Milliman (1974) demonstrou que a variação da composição isotópica ( $\mathrm{C}$ e $\mathrm{O})$ dos carbonatos é resultado direto do tipo de ambiente no qual os carbonatos foram depositados. $\mathrm{O}$ fracionamento isotópico de isótopos de oxigênio é sensível a mudanças de temperatura, por esse motivo a composição isotópica de oxigênio é utilizada para determinar paleotemperaturas; enquanto o fracionamento dos isótopos de carbono está associado a outras condições ambientais.

Em geral, os carbonatos precipitados em ambientes marinhos apresentam valores entre $\delta^{13} \mathrm{C}$ e $\delta^{18} \mathrm{O}_{\mathrm{VPDB}}$ próximos a zero, enquanto os formados em ambiente de água doce apresentam valores mais negativos, entre $-5 \%$ e $-15 \%$ para $\delta^{13} \mathrm{C}$ e entre $-5 \%$ e $-10 \%$ para $\delta^{18} \mathrm{O}_{\mathrm{VPDB}}$.

Neste trabalho, analisou-se a composição isotópica de carbono e oxigênio dos cimentos de arenitos de praia emersos e submersos, com profundidade máxima de $8 \mathrm{~m}$. O cimento dos arenitos emersos apresenta valores de $\delta^{13} \mathrm{C}$ de $-1,1 \%$ a $3,5 \%$, com valor médio de $2,5 \%$, enquanto os submersos mostraram valores de $\delta^{13} \mathrm{C}$ de $3,1 \%$ a $3,4 \%$, com média de $3,3 \%$. Os valores de $\delta^{18} \mathrm{O}_{\mathrm{VPDB}}$ do cimento dos arenitos de praia emersos estão entre $-0,9 \%$ e $0,4 \%$, com média de $-0,0 \%$ das 28 amostras analisadas, e os submersos, de $0,1 \%$ a $0,5 \%$, com média de 0,4\%o (figura 5).

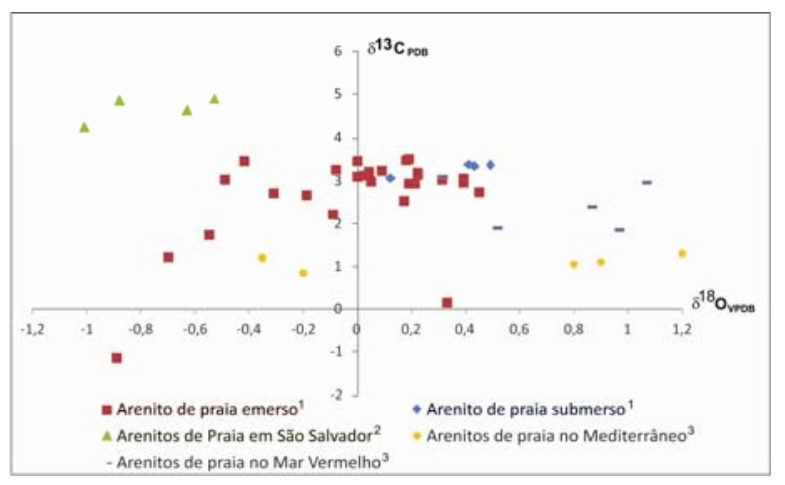

Figura 5: Composição isotópica dos cimentos em arenitos de praia: (1) Fontes desta pesquisa; (2) Beier (1985); Holail \& Rashed (1992)

A média, mediana, variância e desvio padrão calculados apresentam série com pouca variação, destacando-se os dados de carbono, que são menos homogêneos que os de oxigênio (tabela 1). 
Tabela 1: Valores estatísticos da composição de isótopos de carbono e oxigênio dos cimentos de arenitos de praia na costa de Pernambuco

\begin{tabular}{lllllll}
\hline Concentração isotópica & Média & Mediana & Mínimo & Máximo & Variância & Desvio padrão \\
\hline Oxigênio & 0,009 & 0,105 & $-0,89$ & 0,49 & 0,146 & 0,382 \\
Carbono & 2,631 & 3,05 & $-1,12$ & 3,52 & 1,453 & 1,205 \\
\hline
\end{tabular}

Os valores de $\delta^{18} \mathrm{O}$ nos cimentos estudados neste trabalho são superiores aos valores obtidos para cimentos de aragonita das Ilhas Canárias, com média de $-3,6 \%$ para ${ }^{18} \mathrm{O}_{\mathrm{VPDB}}$. Entretanto, eles são inferiores, em relação ao $\delta^{13} \mathrm{C}$, com 4,5\%o (Calvet et al. 2003). Beier (1985) mostrou uma média $-0,88 \%$ para ${ }^{18} \mathrm{O}_{\mathrm{VPDB}}$, em arenitos de praia em São Salvador, valor mais elevado que os arenitos de praia estudados, bem como os valores de $\delta^{13} \mathrm{C}$, com $4,91 \%$.

Os dados de $\delta^{18} \mathrm{O}$ dos arenitos de praia se assemelham aos de Holail \& Rashed (1992), no Mediterrâneo e no Mar Vermelho. Esses autores afirmaram que a pequena variação dos valores de $\delta^{18} \mathrm{O}$ representa temperatura mais ou menos constante, durante a formação do cimento.

Vieira (2005) apresentou os valores para $\delta^{13} \mathrm{C}$ de $7,80 \%$ a $3,57 \%$, e para $\delta^{18} \mathrm{O}_{\text {VPDB }}$, de $-4,41 \%$ a $0,54 \%$ para os cimentos dos arenitos de praia no litoral do Rio Grande do Norte. Segundo a autora, os dados revelaram uma assinatura isotópica uniforme, o que pode ser interpretado como reflexo da composição homogênea do cimento (calcita altamente magnesiana), bem como através da uniformidade dos parâmetros físico-químicos que controlam as rochas, verificados na pequena variedade de valores da paleotemperatura (de $23,3^{\circ} \mathrm{C}$ a $34,9^{\circ} \mathrm{C}$ ).

A plotagem dos dados de $\delta^{13} \mathrm{C}$ e $\delta^{18} \mathrm{O}_{\mathrm{VPDB}}$, nas figuras 6 e 7 , evidencia correlação positiva, com diferenças quanto à sua intensidade para os arenitos de praia emersos e submersos, com coeficientes de determinação $\left(\mathrm{R}^{2}\right)$ iguais a 0,5555 e 0,9475 respectivamente. Isto indica uma correlação regular para os arenitos de praia emersos e uma correlação muito forte para os arenitos de praia submersos. Este último resultado pode ser aparente, tendo em vista a análise de pequeno número de amostras.

A figura 8 foi elaborada seguindo o modelo proposto por Moore (2004), com o objetivo de identificar a origem da assinatura isotópica de $\mathrm{C}$ e $\mathrm{O}$. Observa-se que os valores isotópicos, em quase sua totalidade, inserem-se no campo reservado aos cimentos marinhos. Apenas uma amostra de cimento apresentou valor fora do campo de sedimentos recentes, inserindose no campo de oozes pelágicos, o que sugere que foi formado em ambiente marinho profundo, podendo também ser produto de alteração pós-deposicional.

As amostras que apresentam a composição isotópica de $\mathrm{C}$ e $\mathrm{O}$ típicas de origem marinha são corroboradas pelo parâmetro Z proposto por Keith \& Weber (1964), que evidencia diferenças entre carbonatos marinhos $(Z$ $>120)$ e de água doce $(Z<120)$, e que é calculado a partir da equação:

$$
\begin{gathered}
\mathrm{Z}=\mathrm{a}\left(\delta^{13} \mathrm{C}+50\right)+\mathrm{b}\left(\delta^{18} \mathrm{O}+50\right) \\
\text { Onde } \mathrm{a}=2.048 \mathrm{e} \mathrm{b}=0.498
\end{gathered}
$$

Os valores de $\mathrm{Z}$ obtidos nas amostras analisadas encontram-se entre 124,56 e 134,51 (valor médio de $132,6)$, indicando formação em ambiente marinho.

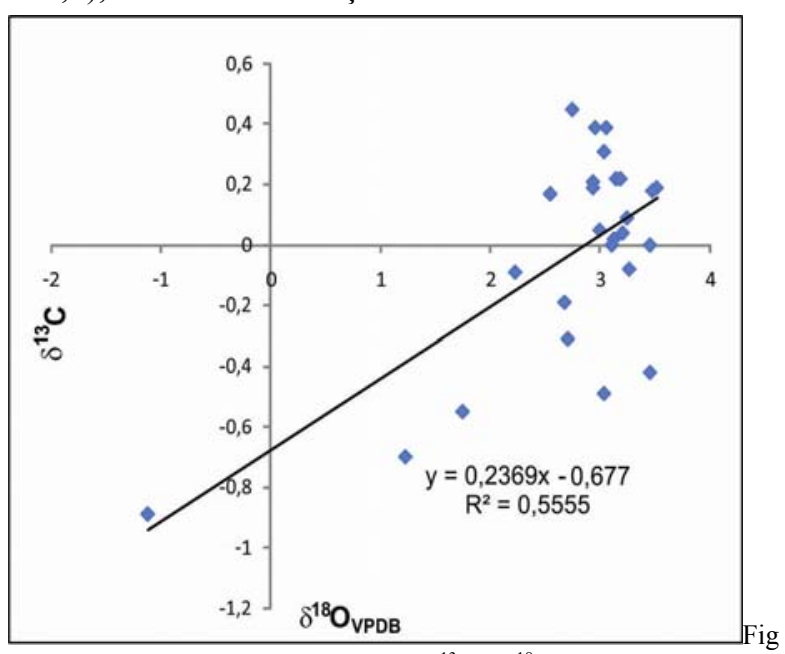

ura 6: Correlação entre os valores de $\delta^{13} \mathrm{C}$ e $\delta^{18} \mathrm{O}_{\mathrm{VPDB}}$, nos arenitos de praia emersos

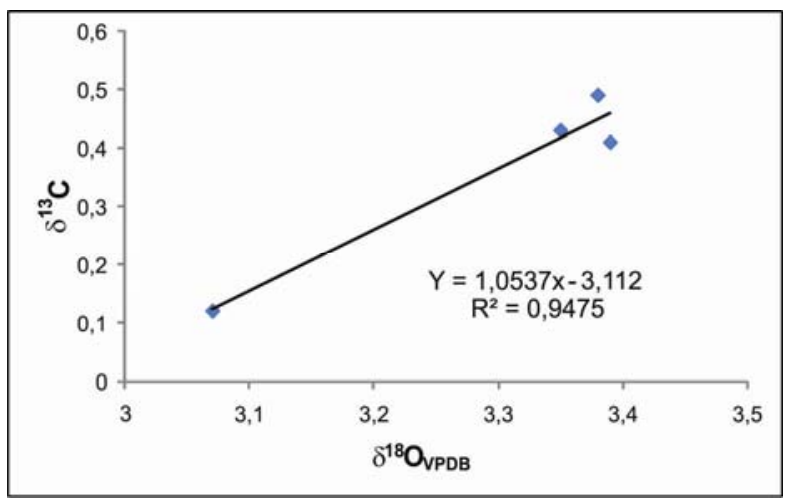

Figura 7: Correlação entre os valores de $\delta^{13} \mathrm{C}$ e $\delta^{18} \mathrm{O}_{\mathrm{VPDB}}$, nos arenitos de praia submersos

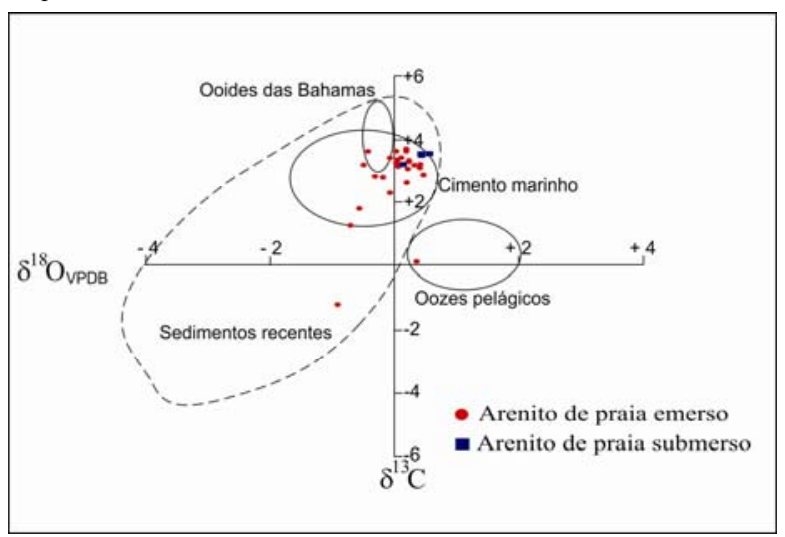

Figura 8: Distribuição de valores de $\delta^{13} \mathrm{C}$ e $\delta^{18} \mathrm{O}_{\mathrm{VPDB}}$ para os vários tipos de cimentos analisados. Modificado de Moore (2004) 
Os dados de $\mathrm{Z}$ e $\delta^{18} \mathrm{O}_{\mathrm{VPDB}}$ são apresentados nas figuras 9 e 10 para representar as amostras de arenitos de praia emersos e submersos, sendo ambas as variáveis com correlação positiva, variando de regular $\left(\mathrm{R}^{2}=0,425\right)$ para os corpos emersos, a muito forte $\left(\mathrm{R}^{2}=0,9602\right)$ para os submersos.

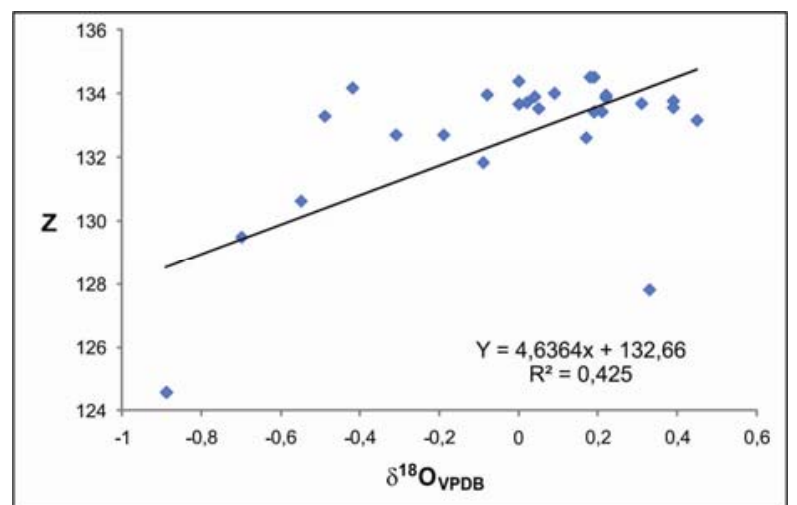

Figura 9: Correlação entre os valores de $\mathrm{Z}$ e $\delta^{18} \mathrm{O}_{\mathrm{VPDB}}$, nos arenitos de praia emersos

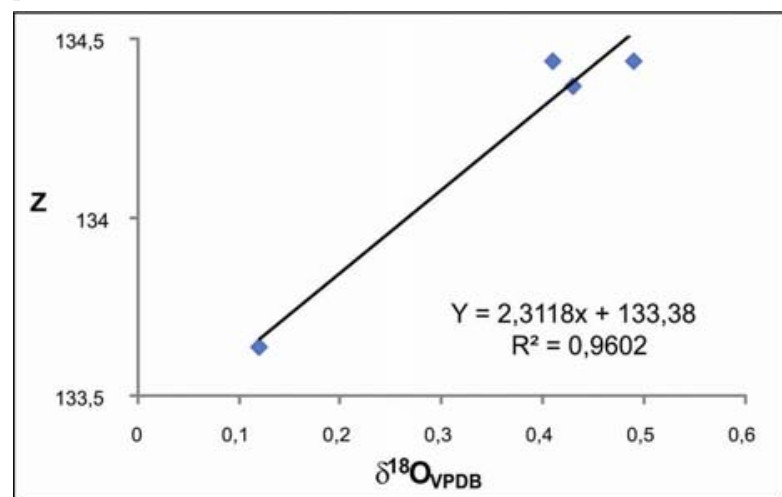

Figura 10: Correlação entre os valores de $\mathrm{Z}$ e $\delta^{18} \mathrm{O}_{\mathrm{VPDB}}$, nos arenitos de praia submersos

Os valores de $\mathrm{Z}$ e $\delta^{13} \mathrm{C}$ também indicam correlação positiva entre amostras emersas e submersas, com coeficientes de correlação $\mathrm{R}^{2}=0,997$ e $\mathrm{R}^{2}=0,9987$, respectivamente, indicando correlação muito forte para ambas as amostras estudadas (figuras 11 e 12 ).

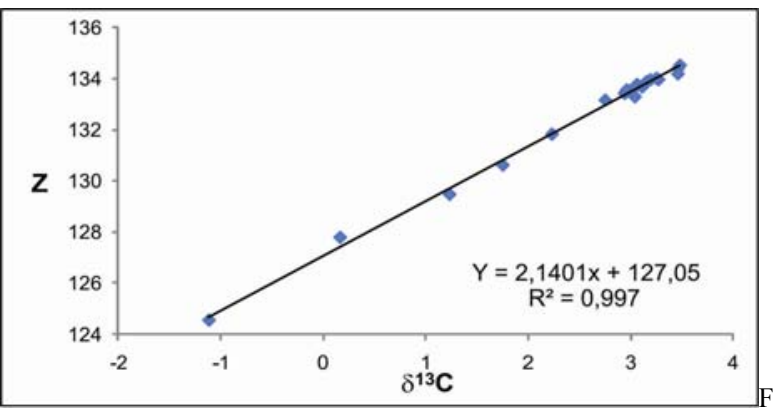

igura 11: Correlação entre os valores de $\mathrm{Z}$ e $\delta^{13} \mathrm{C}$, nos arenitos de praia emersos

É possível determinar a paleotemperatura da água da qual um carbonato se precipitou, a partir de sua composição isotópica de oxigênio, tendo como princípio as reações de troca entre o oxigênio do carbonato de cálcio e da água do mar do qual ele se precipitou, sob condições de equilíbrio. Muitas equações têm sido publicadas para determinar o valor da paleotemperatura da água. Neste estudo, utilizou-se a equação de Irwin et al. (1977).

$$
\mathrm{T}=16,9-4,21(\delta \mathrm{c}-\delta \mathrm{w})+0,14(\delta \mathrm{c}-\delta \mathrm{w})^{2}
$$

Onde $(\delta c-\delta w)$ é a diferença da medida de $\delta^{18} \mathrm{O}_{\mathrm{VPDB}}$ da calcita e da água.

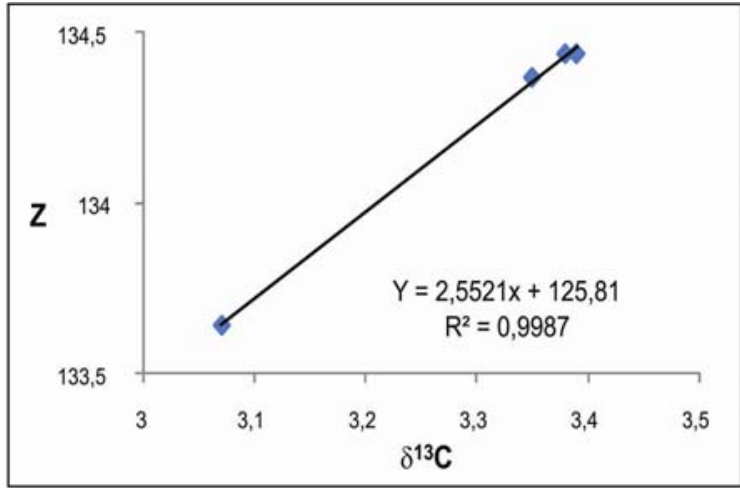

Figura 12: Correlação entre os valores de $\mathrm{Z}$ e $\delta^{13} \mathrm{C}$ nos arenitos de praia submersos

$\mathrm{Na}$ figura 13, observa-se uma tendência negativa entre a temperatura e valores de $\delta^{18} \mathrm{O}_{\mathrm{VPDB}}$. A paleotemperatura deduzida dos arenitos de praia submersos varia de $22,8^{\circ} \mathrm{C}$ a $24,2^{\circ} \mathrm{C}$, enquanto para os arenitos de praia emersos varia de $22,9^{\circ} \mathrm{C}$ a $28,2^{\circ} \mathrm{C}$. Estes valores são compatíveis com a temperatura atual da água do mar na área.

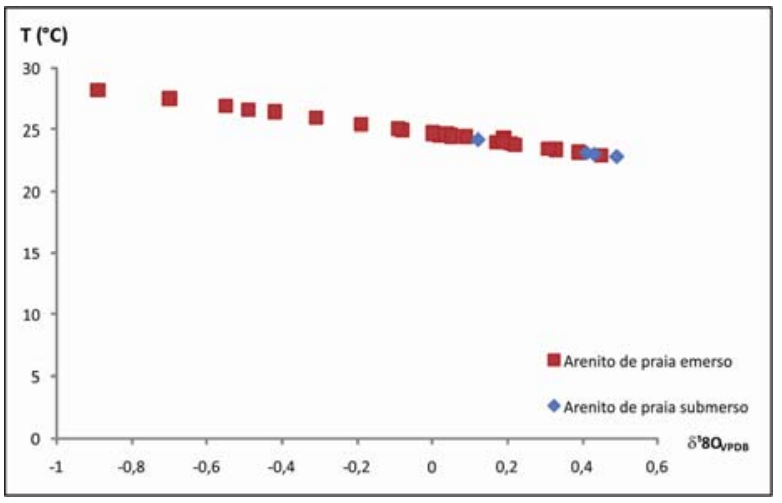

Figura 13: Distribuição de valores de temperatura e $\delta^{18} \mathrm{O}_{\mathrm{VPDB}}$

\section{Conclusão}

A constituição litológica das rochas estudadas é composta por arenitos médios a muito grossos e arenitos conglomeráticos, com granodecrescência ascendente. Em geral, apresentam grãos de quartzo arredondados, moderadamente selecionados, bastante fraturados, e com bordas corroídas, o que evidencia processo de compactação mecânica e a ação de dissolução durante a diagênese superficial. A diagênese superficial resultou em condições para uma dissolução parcial dos grãos, sobretudo de quartzo. A 
predominância de grãos flutuantes indica um baixo grau de diagênese, e a porosidade dominante é do tipo interpartícula. $\mathrm{O}$ preenchimento por calcita magnesiana nos espaços porosos reduziu significamente a porosidade.

O cimento dos arenitos de praia é constituído unicamente de calcita rica em $\mathrm{Mg}^{2+}$, caracterizando ambientes de deposição sob forte influência marinha, mais especificamente de precipitação na zona de estirâncio, o que é confirmado pelas análises geoquímicas. Foram identificadas seis formas do cimento carbonático: (i) cutícula criptocristalina; (ii) franja prismática isópaca; (iii) agregados pseudopeloidais; (iv) agregados fibrorradiais; (v) micrítico; e (vi) equigranular. Além destas fases cimentantes, identificou-se marga infiltrada.

A análise de isótopos de oxigênio, nas amostras dos arenitos estudadas, apresentam valores de $\delta^{18} \mathrm{O}_{\mathrm{VPDB}}$ para os arenitos de praia emersos entre $-0,9 \%$ e $0,4 \%$, com média de $-0,0 \%$, e para os submersos, valores de $\delta^{18} \mathrm{O}_{\mathrm{VPDB}}$ de $0,1 \%$ a $0,5 \%$, com média de $0,4 \%$. Os valores isotópicos de carbono e feições diagenéticas indicam que a precipitação do cimento ocorreu em ambiente marinho.

A paleotemperatura deduzida do cimento dos arenitos de praia submersos varia de $22,8^{\circ} \mathrm{C}$ a $24,2^{\circ} \mathrm{C}$, enquanto para os emersos varia de $22,9^{\circ} \mathrm{C}$ a $28,2^{\circ} \mathrm{C}$. Apesar de pequena diferença de profundidade $(6 \mathrm{~m})$ entre os arenitos de praia emersos e submersos, observa-se diminuição da temperatura da água com o aumento da profundidade. Estes dados revelam que a cimentação ocorreu de cima para baixo, e isto representa, provavelmente, o rebaixamento do nível do mar durante o Holoceno.

Os valores de $\delta^{18} \mathrm{O}_{\mathrm{VPDB}}$ dos arenitos de praia estão entre $-0,9 \%$ e $0,5 \%$ e indicam que a paleotemperatura da água da qual estes carbonatos se precipitaram variou moderadamente. De acordo com Coudray e Montaggioni (1986), valores entre $-0,9 \%$ e $0,5 \%$ para $\delta^{18} \mathrm{O}_{\mathrm{VPDB}}$ são característicos para deposição na zona de estirâncio.

Dados de $\delta^{13} \mathrm{C}$ e $\delta^{18} \mathrm{O}$ apresentados por Guerra et al. (2005), para cimento em arenitos de praia na Ilha de Itamaracá (de $-2,0 \%$ a $3,6 \%$ para $\ddot{a}^{13} \mathrm{C}$ e de $-2,1 \%$ a $1,3 \%$ para $\left.\delta^{18} \mathrm{O}_{\mathrm{VPDB}}\right)$ se aproximam aos valores apresentados nesta pesquisa. Guerra et al. (2005) sugerem que a cimentação ocorreu em água meteóricavadosa e/ou marinha-freática, por perda de $\mathrm{CO}_{2}$ durante a evaporação da água intersticial.

\section{Agradecimentos}

Os autores agradecem ao $\mathrm{CNPq}$, pelo financiamento do projeto de pesquisa (Edital Universal - 014/2010); à CAPES através do projeto Ciências do Mar (23038.051660/2009-73) e a contribuição do Laboratório de Isótopos Estáveis do Departamento de Geologia da Universidade Federal de Pernambuco.

\section{Referências}

Alexandersson T. 1972. Intergranular growth of marine aragonite and $\mathrm{Mg}$ calcite: evidence of precipitation from supersaturated sea-water. Journal of Sedimentary Petrology, 42: 441-460.

Beier J.A. 1985. Diagenesis of Quaternary Bahamian beachrock: petrographic and isotopic evidence. Journal of Sedimentary Petrology, 55:755-761.

Branner J.C. 1904. The stone reefs of Brazil, their geological and geographical relations with a chapter of the coral reefs. Harvard Coll. Mus. Comp. Zool. Bull., 44: 1-285.

Calvet F., Cabrera M.C., Carracedo J.C., Mangas J., Perez-Torrado F.J., Recio C., Trave A. 2003. Beachrocks from the island of La Palma (Canary Islands, Spain). Marine Geology, 197:75-93.

Coudray J., Montaggioni L. 1986. The diagenetic products of marine carbonate as sea level indicators. In: O. Plassche (Ed.), Sea-level research: a manual for the collection and evaluation of data. Geo Books, Norwich, p. 311-360.

Craig H. 1957. Isotopic standards for carbon and oxygen correction factors for mass spectrometric analysis of carbon dioxide. Geochimica et Cosmochimica Acta, 12:133-149.

Darwin C. 1841. On a remarcable bar of sandstone of Pernambuco on the coast of Brazil. Magazin \& Journal Sciences, London, p. 257-261.

Ginsburg R.N., James N.P. 1953. Beach rock in South Florida. J. Sedimentary Petrology, 23:85-92.

Guerra N.C., Kiang C.F., Sial A.N. 2005. Carbonate cements in contemporaneous beachrocks, Jaguaribe beach, Itamaracá island, northeastern Brazil: petrographic, geochemical and isotopic aspects. Anais da Academia Brasileira de Ciências. 77(2): 343352.

Holail H., Rashed M. 1992. Stable isotopic composition of carbonate-cemented recent beachrock along the Mediterranean and Red Sea Coasts of Egypt. Marine Geology, 106:141-148.

Irwin H., Curtis C., Coleman M. 1977. Isotopic evidence for source of diagenetic carbonates formed during burial of organic-rich sediments. Nature, 269: 209-213.

Jones B., Rossen M.R., Renault R.W. 1997. Silica-cemented beachrock from lake Taupo, North Island, New Zealand. Journal of Sedimentary Research, 67:805-814.

Kahn J.S. 1956. The analysis and distribuition of the properties of packing in sand-size sediments. 1. On the measurement of packing in sandstones. Journal of Geology, 64:385-395.

Keith M.L., Weber J.N. 1964. Carbon and oxygen isotopic composition of selected limestones and fossils. Geochimica et Cosmochimica Acta, 28: 1787-1816.

Kneale D., Viles H.A. 2000. Beach cement: incipient CaCO3cemented beachrock development in the upper intertidal zone, North Uist, Scotland. Sedimentary Geology, 132:165-170.

Longman M.W. 1980. Carbonate diagenetic textures from nearsurface diagenetic environments. AAPG Bulletin. 64:461487.

Mabesoone J.M. 1964. Origin And Age Of The Sandstone Reefs Of Pernambuco (Northeastern Brazil). J. Sedimentary Petrology, 34:715-726.

Milliman D. 1974. Marine Carbonates. Springer-Verlag, Berlin, 375 p.

Moore C.H. 2004. Carbonate reservoirs - Porosity evolution and diagenesis in a sequence stratigraphic framework. Developments in Sedimentology 55, Elsevier, 444 p.

Neumeier U. 1999. Experimental modelling of beachrock cementation under microbial influence. Sedimentary Geology, 126:35-46.

Omoto K. 2001. Radiocarbon ages of beach rocks and Late Holocene sea-level changes in the southern part of the Nansei Islands, Southwest of Japan. Radiocarbon, 43:887-898.

Rey D., Rubio B., Bernabeu A.M., Vilas F. 2004. Formation, exposure, and evolution of a high-latitude beachrock in the intertidal zone of the Corrubedo complex (Ria de Arousa, Galicia, NW Spain). Sedimentary Geology, 169:93-105.

Russell R.J. 1962. Origin of beachrock. Zeitschrift für Geomorphologie, 6:1-16.

Vieira M.M. 2005. Aspectos sedimentológicos e petrológicos dos beachrocks do Estado do Rio Grande do Norte. (Doutorado em Geociências) - Universidade Federal do Rio Grande do Sul. Porto Alegre. 
Vousdoukas M.I., Velegrakis A.F., Plomaritis T.A. 2007. Beachrock occurrence, characteristics, formation mechanisms and impacts. Earth-Science Reviews, 85:23-46.

Wentworth C.K. 1922. A scale of grade and class terms for clastic sediments. Journal of Geology, 30:377-392. ${ }^{\text {i. }}$

Recebido 06 de novembro de 2012 Aceito 09 de outubro de 2013 